\title{
Sclerosing Epithelioid Fibrosarcoma
}

National Cancer Institute

\section{Source}

National Cancer Institute. Sclerosing Epithelioid Fibrosarcoma. NCI Thesaurus. Code C49027.

A well-circumscribed rare morphologic variant of fibrosarcoma, that arises from the soft tissue. It is characterized by the presence of nests of malignant epithelioid fibroblasts and sclerotic collagen stroma formation. 